\title{
Biochemical Syndrome in Adult Pyloric Stenosis, a Clue to Diagnosis in Emergency Department
}

\author{
Ahmed M. Badi1 ${ }^{*}$, Vamanjore A. Naushad2, Abraham John², Khalid H. Elnour ${ }^{2}$ \\ ${ }^{1}$ Department of Medicine-Gastroenterology, Al Khor Hospital, Hamad Medical Corporation, Doha, Qatar \\ ${ }^{2}$ Department of Emergency, Al Khor Hospital, Hamad Medical Corporation, Doha, Qatar \\ Email: ${ }^{*}$ dr.ahmedbadi86@yahoo.com
}

Received 2 October 2014; revised 16 November 2014; accepted 4 December 2014

Copyright (C) 2014 by authors and Scientific Research Publishing Inc.

This work is licensed under the Creative Commons Attribution International License (CC BY). http://creativecommons.org/licenses/by/4.0/

c) (i) Open Access

\begin{abstract}
Characteristic biochemical changes have been documented in patients presenting with the symptoms and signs of gastric outlet obstruction. These changes usually consist of hypochloremic, hypokalemic metabolic alkalosis and hypocalcaemia with or without renal failure. The aim of this report is to highlight these biochemical abnormalities again. Moreover, we suggest conversely that the presence of these changes should prompt the clinician for further evaluation to rule out gastric outlet obstruction especially in the emergency department. Early intervention resulted in dramatic improvement in patient's clinical and biochemical status.
\end{abstract}

\section{Keywords}

Peptic, Ulcer, Gastric, Outlet, Obstruction, Metabolic, Alkalosis

\section{Introduction}

Gastric outlet obstruction (GOO) is not considered a single entity; rather it is the clinical and pathophysiological consequence of any disease process that produces a blockade to gastric emptying. GOO is divided into two groups on the basis of its causes: benign and malignant. One review shows that only $37 \%$ of patients with GOO have benign disease and the remaining patients have obstruction due to malignancy [1]. The major benign causes of GOO are peptic ulcer disease (PUD), gastric polyps, ingestion of caustics, gallstone obstruction (Bouveret syndrome), pancreatic pseudo cysts.

The incidence of gastric outlet obstruction (GOO) has been reported to be less than $5 \%$ in patients with PUD,

${ }^{*}$ Corresponding author.

How to cite this paper: Badi, A.M., Naushad, V.A., John, A. and Elnour, K.H. (2014) Biochemical Syndrome in Adult Pyloric Stenosis, a Clue to Diagnosis in Emergency Department. Open Journal of Gastroenterology, 4, 378-382. 
which is the leading benign cause of the problem [2].

Pancreatic cancer is the most common malignancy causing GOO. Outlet obstruction may occur in $10 \%-20 \%$ of patients with pancreatic carcinoma. Other tumors that may obstruct the gastric outlet include distal gastric cancer, duodenal cancer, and metastases to the gastric outlet also may be caused by other primary tumors.

Patients present with intermittent symptoms that progress until obstruction is complete. Vomiting is the common symptom; initially, patients may tolerate liquids than solid food.

In a later stage, patients may develop significant weight loss due to poor intake. Malnutrition is a late sign, but it may be very obvious and appear early in patients with concomitant malignancy.

Continuous vomiting may lead to dehydration and electrolyte abnormalities. The patient we report develop electrolytes disturbance as sequel of persistent vomiting.

Nowadays with the advent of proton pump inhibitors and Helicobacter pylori eradication treatment the incidence of gastric outlet obstruction (GOO) due to peptic ulcer disease has reduced drastically in the last two decades. However, few scattered cases are still being reported both in young and older patients [3]-[7]. Understanding the biochemical changes in pyloric stenosis is important for the diagnosis because of the fact that the classical presentation of projectile vomiting and a succession splash may not be present in all the patients, and the facility for the endoscopy may not be readily available in all the centers. The biochemical syndrome of hypochloremic, hypokalemic, severe metabolic alkalosis with or without renal failure can lead to cardiac arrhythmias, seizures and even death. Hence a high index of suspicion based on these biochemical aberrations is necessary for the early diagnoses, specific referral which in turn will lead to early initiation of appropriate treatment and reduction of complications [8] [9]. We report a case with benign cause of GOO but complicated with biochemical syndrome.

\section{Case Report}

A 29-year-old gentleman presented to the Emergency Department (ED) with the complaints of repeated vomiting for the past 10 days associated with mild epigastric pain and generalized weakness. He had lost $10 \mathrm{~kg}$ in the last few days. He denied history of melena, hematemesis, fever, chest pain, cough, shortness of breath. His past medical history revealed dyspeptic symptoms on and off for the past few years but had not been evaluated. The patient denied history of having hypertension, diabetes mellitus, coronary artery disease, bronchial asthma or liver disease in the past. He was not on any medications and he denied consumption of alcohol. He used to smoke 8 - 10 cigarettes per day for the past 10 years.

On arrival to the ED: He was dehydrated. His vitals were: pulse rate: 100/min, BP: 105/64 mmHg, respiratory rate: $19 / \mathrm{min}, \mathrm{SpO}_{2}-100 \%$, Temperature: $36.5^{\circ} \mathrm{C}$. Examinations of cardiovascular, pulmonary, genitourinary, central nervous system and abdomen were within normal limits. The results of initial blood investigations are shown in Table 1 \& Table 2 and normal values are seen between the brackets. ECG and radiological work

Table 1. Blood chemistry results on arrival to ED.

\begin{tabular}{cc}
\hline Urea & $13.5 \mathrm{mmol} / \mathrm{L}(1.7-8.3)$ \\
Creatinine & $137 \mu \mathrm{mol} / \mathrm{L}(62-124)$ \\
Sodium & $131 \mathrm{mmol} / \mathrm{L}(135-145)$ \\
Potassium & $2.5 \mathrm{mmol} / \mathrm{L}(3.6-5.1)$ \\
Chloride & $75 \mathrm{mmol} / \mathrm{L}(96-110)$ \\
\hline Table 2. Arterial blood gases $(\mathrm{ABG})$ on $\mathrm{arrival}$ to ED. \\
\hline $\mathrm{pH}$ & $7.548 \mathrm{H}(7.35-7.45)$ \\
$\mathrm{pCO}_{2}$ & $64.1 \mathrm{mmHg}(35-48)$ \\
Plasma bicarbonate & $55.7 \mathrm{mmol} / \mathrm{L}(21-28)$ \\
Total CO $_{2}$ & $57.7 \mathrm{mmol} / \mathrm{L}(22-29)$ \\
$\mathrm{pO}_{2}$ & $100 \%$
\end{tabular}


up (Chest X-ray and plan abdominal CT scan) were normal. An initial bedside ultrasound examination showed gastric distension, prominent peristaltic wave and mottled retained gastric contents (caterpillar sign). In the ED he was resuscitated with intravenous fluids, parenteral ranitidine, metoclopramide, and potassium chloride. Diagnostic endoscopy and balloon dilatation of the pyloric channel was performed on the next morning.

\section{Description of the Procedure}

Under conscious sedation, upper endoscopy was performed which showed retention GERD (Los Angeles class c) (Figure 1), pyloric channel ulcer (Figure 2) causing gastric outlet obstruction (Figure 3). CLO test (Rapid urease test for $H$. pylori) was positive.

A wire-guided balloon was introduced and pushed through the narrowed segment (Figure 4). At a suitable position, inflation of the balloon was started with gradually increasing diameters of 8,10 and $12 \mathrm{~mm}$. The pressure was maintained for two minutes. After dilatation was achieved, the scope was pushed through the narrowed segment into the duodenum with difficulty. The scope itself was used to complete the dilatation by gentle maneuvering.

Patient was monitored for signs and symptoms of perforation or bleeding for 6 hours after the procedure. He started liquid diet on the same day and soft diet on the next day after the procedure. Triple therapy was started giving positive CLO test and he was discharged from the hospital after 5 days. All his biochemical parameters were normal before discharge. Follow up endoscopy was performed after two weeks to assess the persistence of dilatation which showed adequate dilatation.

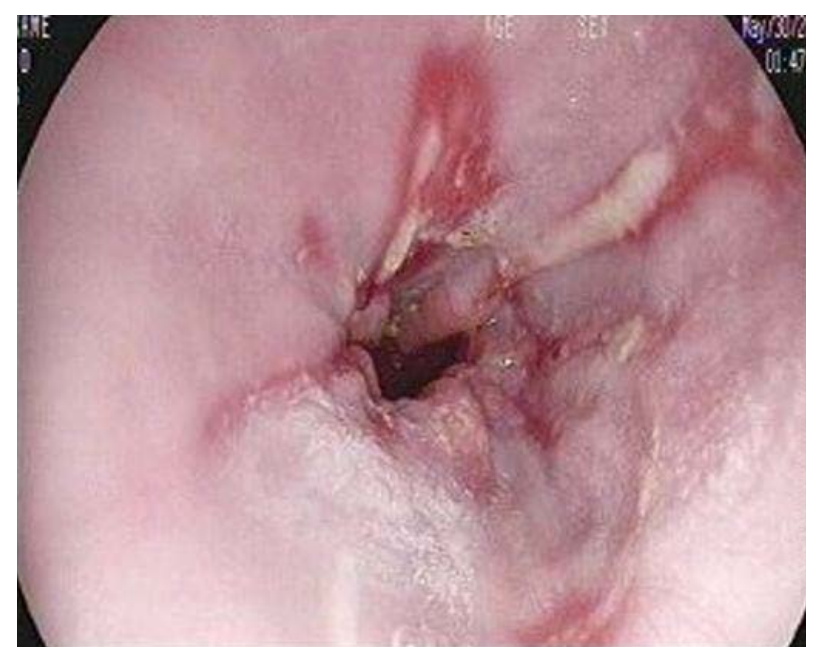

Figure 1. Gastroesophgeal reflux disease Los Angeles class c.

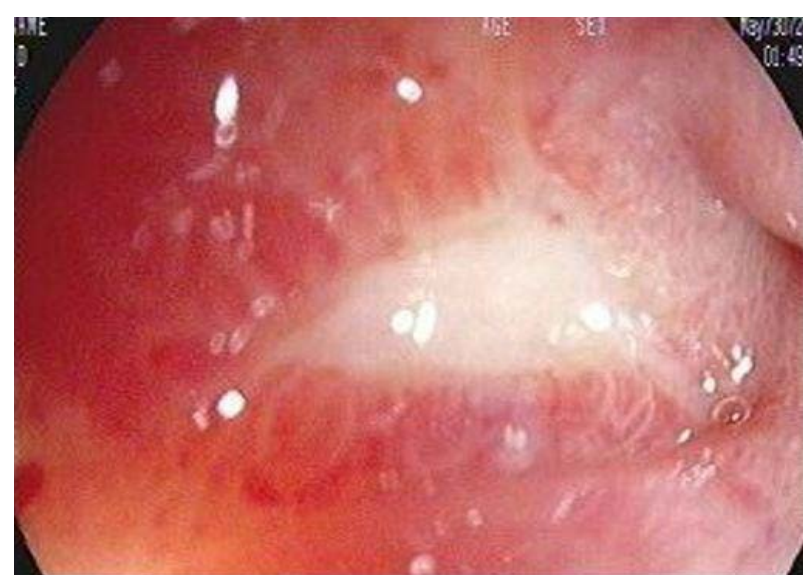

Figure 2. Pyloric channel ulcer. 


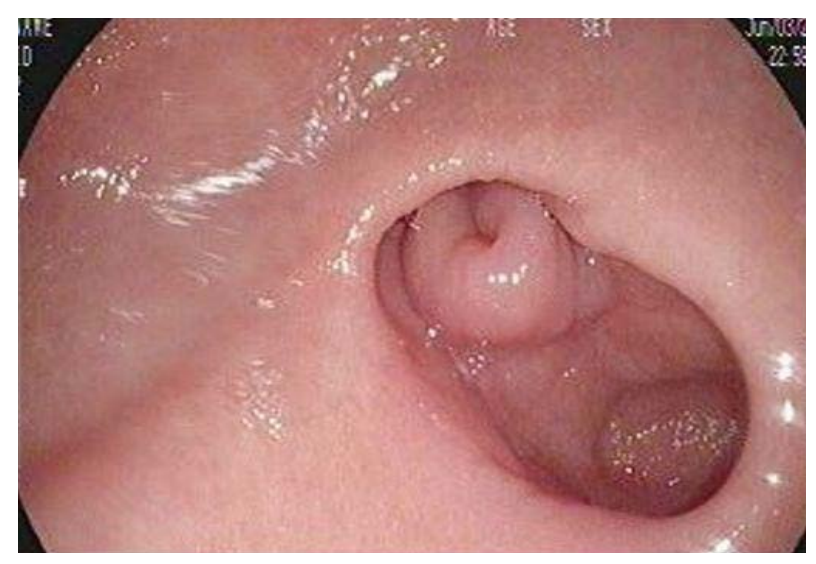

Figure 3. Pyloric stenosis.

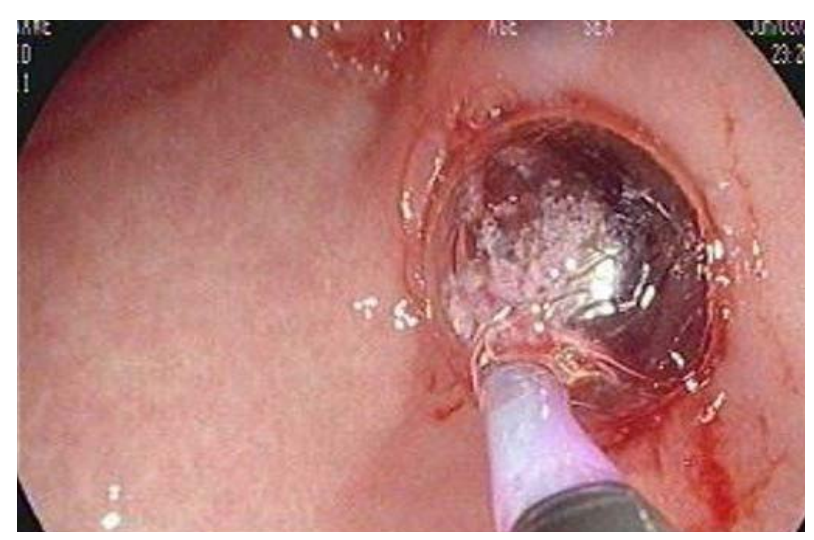

Figure 4. Balloon dilatation.

\section{Discussion}

The pathophysiology of metabolic changes in pyloric stenosis is multifactorial. Persistent vomiting will lead to relative intracellular acidosis due to the movement of potassium out of the cells to correct the hypokalemia and influx of hydrogen ions into the cells for maintaining neutrality [6]. Moreover, vomiting of gastric hydrochloric acid will also result in hypochloremia.

Metabolic alkalosis develops because of an increase in the plasma bicarbonate concentration and increased renal reabsorption of bicarbonate caused by stimulation of sodium-hydrogen exchange by intracellular acidosis [10]. Furthermore, in the presence of hypokalemia kidneys preferentially excrete hydrogen via the H-K-adenosine triphosphate pump to maintain the potassium levels, further worsening the alkalosis [5]. Metabolic alkalosis will also lead to reduction in circulating ionized calcium [11].

Renal failure in GOO is due to both prerenal and renal factors; dehydration caused by persistent vomiting will lead to reduced renal perfusion and prerenal failure. Furthermore increased rennin-aldosterone secretion due to hypovolemia results in further reduction of glomerular perfusion [5]. If not corrected early and promptly it will result in acute tubular necrosis. Consequently, these vital biochemical changes which can adversely affect the patient especially if he/she is elderly with other co-morbidity, for that reason the early diagnosis and treatment are crucial.

Management of our patient started with initial resuscitation using intravenous fluids was employed to correct his electrolyte disturbance, and then was prepared for gastroscopy and balloon dilatation. Of note, correction of GOO reversed the biochemical changes completely.

\section{Conclusions}

Gastric outlet obstruction can be a diagnostic and treatment dilemma as the presentations are seen in a variety of 
clinical scenarios.

Getting serum electrolytes and ABG is an essential first step in management of patient with persistent vomiting to assess the patient's volume status and possible electrolyte imbalance. Diagnosis of gastric outlet obstruction should be in differentials of such cases and needs a high index of suspicion. Early diagnosis and prompt management are lifesaving. While mild cases of GOO could be treated on outpatient basis, severe cases with significant electrolytes disturbances mandate in patient management.

\section{Competing Interests}

All the authors declare that there are no competing interests.

\section{Consent}

Informed consent was obtained from the patient.

\section{References}

[1] Andersson, A. and Bergdahl, L. (1977) Carcinoid Tumors of the Appendix in Children. A Report of 25 Cases. Acta Chirurgica Scandinavica, 143, 173-175.

[2] Gibson, J.B., Behrman, S.W., Fabian, T.C. and Britt, L.G. (2000) Gastric Outlet Obstruction Resulting from Peptic Ulcer Disease Requiring Surgical Intervention Is Infrequently Associated with Helicobacter Pylori Infection. Journal of the American College of Surgeons, 191, 32-37. http://dx.doi.org/10.1016/S1072-7515(00)00298-2

[3] Siow, S.L., Wong, C.M. and Sohail, M. (2009) Adult Pyloric Stenosis Masquerading as Acute Renal Failure. Medical Journal of Malaysia, 64, 168-169.

[4] Ahmad, J., Thomson, S., Taylor, M. and Scoffield, J. (2011) A Reminder of the Classical Biochemical Sequelae of Adult Gastric Outlet Obstruction. BMJ Case Reports.

[5] Mohammed, A.A., Benmousa, A., Almeghaiseeb, I. and Alkarawi, M. (2007) Gastric Outlet Obstruction. Hepatogastroenterology, 54, 2415-2420.

[6] Garry, P., Tormey, W.P. and Harte, M. (1993) Arterial Blood pH of 7.95 in an Adult with Pyloric Stenosis. Clinical Chemistry, 39, 1554-1555.

[7] David, P.B., Daniel, J.B. and Brent, M.F. (2013) Profound Alkalemia Secondary to Gastric Outlet Obstruction and Acute Renal Insufficiency. American Journal of Emergency Medicine, 31, 444.e1-444.e3.

[8] Mccauley, M., Gunawardane, M. and Cowan, M. (2006) Severe Metabolic Alkalosis Due to Pyloric Obstruction: Case Presentation, Evaluation and Management. The American Medical Sciences, 332, 346-50.

[9] Das, A.K. and Patil, V. (2006) Adult Pyloric Stenosis—A Forgotten Entity. Age and Ageing, 35, 448. http://dx.doi.org/10.1093/ageing/afl021

[10] Wiseman, A.C. and Linas, S. (2005) Disorders of Potassium and Acid-Base Balance. American Journal of Kidney Disease, 45, 441-452.

[11] Pethe-Konard, K. and Stasiow, B. (1997) A Case of Tetany in a 23 Years Old Patient as the First Manifestation of Chronic Pyloric Stenosis. Polski Merkuriusz Lekarski, 2, 345-346. 
Scientific Research Publishing (SCIRP) is one of the largest Open Access journal publishers. It is currently publishing more than 200 open access, online, peer-reviewed journals covering a wide range of academic disciplines. SCIRP serves the worldwide academic communities and contributes to the progress and application of science with its publication.

Other selected journals from SCIRP are listed as below. Submit your manuscript to us via either submit@scirp.org or Online Submission Portal.
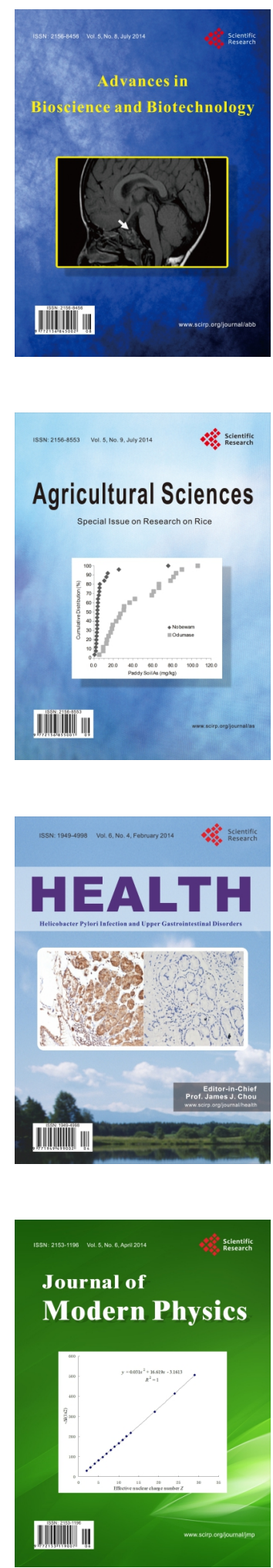
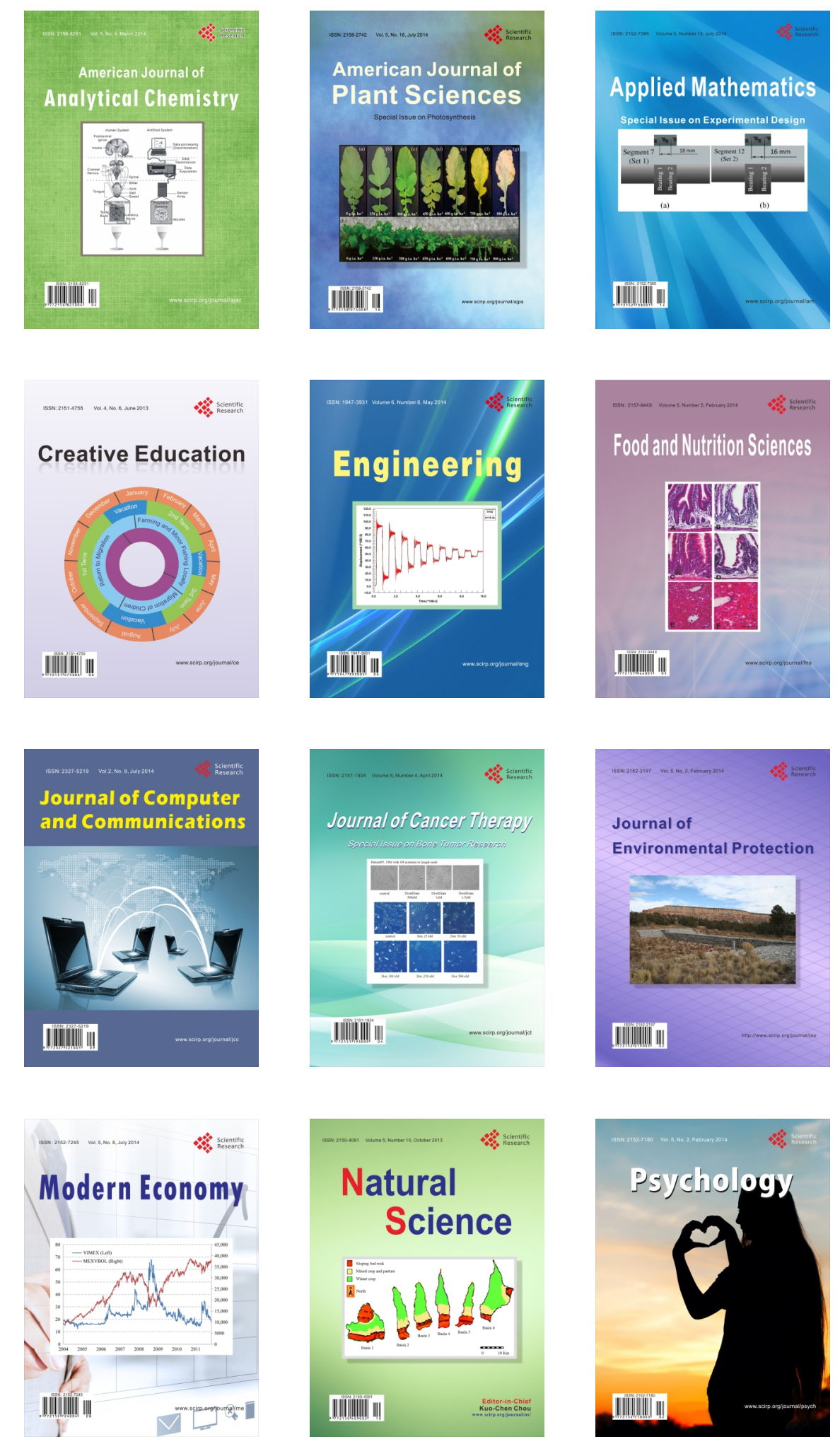